\title{
Postpartum depression in Recife - Brazil: prevalence and association with bio-socio-demographic factors
}

\author{
Depressão pós-parto em Recife - Brasil: prevalência e associação com fatores \\ biossociodemográficos
}

Amaury Cantilino', Carla Fonseca Zambaldi', Thiago Lucena César de Albuquerque², Juliana Alencar Paes², Ana Carla Peres Montenegro², Everton Botelho Sougey²

\section{ABSTRACT}

Objective: To use a semi-structured interview to detect depression in postpartum women according to the criteria proposed by the DSM in child health care clinics in the city of Recife, together with the proper association of this disorder to bio-socio-demographic data. Methods: The study used a cross-section method and contained a convenience sample of 400 women that were between 2 and 26 weeks of postpartum in child health care clinics. A bio-socio-demographic questionnaire and the Portuguese version of the Structured Clinical Interview for DSM-IV Axis I Disorders were used. Results: Twenty nine of the mothers (7.2\%) were diagnosed as suffering from postpartum depression. Women with a past history of psychiatric disorders, a family history of psychiatric disorder and some sort of clinical complication presented a higher prevalence of depression. The same happened to those with a past history of spontaneous abortion, those who had a transpelvic birth

\section{Keywords}

Postpartum depression, prevalence, risk factors, Brazil. and those over 8 weeks of puerperium. Conclusion: The rate of postpartum depression in this sample, 7.2\%, was lower than that reported by other Brazilian studies. It probably occurred because the other researchers used screening scales to assess this estimate instead of a clinical interview.

\section{RESUMO}

Objetivo: Utilizar uma entrevista clínica semiestruturada para a detecção de depressão em muIheres puérperas, de acordo com os critérios do DSM em serviços de puericultura da cidade do Recife, juntamente com uma apropriada associação entre esse transtorno e dados biossociodemográficos. Métodos: $\mathrm{O}$ estudo utilizou um corte transversal e teve uma amostra de conveniência de 400 mulheres que levavam seus bebês para ambulatórios de puericultura e que estavam entre 2 e 26 semanas de pós-parto. Um questionário biossociodemográfico e a versão em português do Structured Clinical Interview for DSM-IV Axis I Disorders foram utilizados. Resultados: Vinte e nove das mães (7,2\%) foram diagnosticadas como tendo depressão pós-parto. Mulheres com história pregressa de transtornos mentais, história familiar de transtornos mentais e com alguma complicação médica geral apresentaram prevalência maior de depressão. O mesmo ocorreu com aquelas com história anterior de abortamento espontâneo, aquelas que haviam tido parto transpelviano e aquelas que estavam com mais de 8 semanas de puerpério. Conclusão: A taxa de depressão pós-parto na nossa amostra, 7,2\%, foi menor do que aquelas relatadas em outros estudos brasileiros. Isso provavelmente ocorreu porque os outros pesquisadores utilizaram instrumentos de triagem para depressão em vez de entrevistas clínicas. risco, Brasil.

1 Universidade Federal de Pernambuco (UFPE), Programa de Saúde Mental da Mulher. 2 Universidade Federal de Pernambuco (UFPE).

Recebido em 8/1/2010 Aprovado em $8 / 2 / 2010$
Endereço para correspondência: Amaury Cantilino Av. Domingos Ferreira, 2160, sala 108 - 51111-020 - Recife, PE Telefax: 55 (81) 3463-4706 E-mail: cantilino@hotmail.com 


\section{INTRODUCTION}

Depressive disorder is characterized by a persistent depressed mood, decreased pleasure and interest in usual activities, disturbances in appetite, sleep, psychomotor function, energy level, concentration, and self-worth. It is a significant health problem affecting $5 \%$ a $9 \%$ of the women in point prevalence studies'.

Some researchers suggest that there is a higher rate of depression during the postpartum period. In a study carried out during the 80 's, researchers compared the prevalence of depression before and after delivery. They followed a group of women from the beginning of pregnancy until the third month of puerperium. The results showed a prevalence of $10 \%$ in the first trimester of gestation and $14 \%$ in the first trimester postpartum².

In a recently published review, the authors found 143 studies reporting on the rates of postpartum depression (PPD) in 40 countries. Most of them were carried out in economically developed western countries. The observed prevalence of this disorder varied from 0 to $60 \%$ among the various studies. In some countries, such as Singapore, Malta, Malaysia, Austria and Denmark there are low PPD prevalence when compared to Brazil, Costa Rica, Italy, South Africa, Taiwan and Korea, where the studies showed considerably high rates. The authors attribute this variation to cultural factors (levels of social support and stress), economic situation (poverty and nutrition), differences in perception regarding mental disease and stigma, and biological vulnerability factors ${ }^{3}$.

One of the hypotheses that must be considered to explain the variability is the fact that different diagnostic instruments were used to characterize PPD. Very few studies today use the diagnostic criteria suggested in the Diagnostic and Statistical Manual of the American Psychiatric Association (DSM), or the International Classification of Diseases of the World Health Organization (ICD), with the use of specific semi-structured interviews recommended for diagnostic precision. Most of the studies used the Edinburgh Postnatal Depression Scale (EPDS) ${ }^{4}$, and some used the Beck Depression Inventory (BDI) $)^{5}$. The problem is that, although these scales are very useful for screening those women that can be depressed, they were not designed to give a postpartum depression diagnosis as they are self-report scales. Their positive predictable values vary considerably among different cultures. When these scales are used for diagnosis, the depression rate can be overestimated due to a significant number of false positives for prevalence studies.

In another point of view, the rates of postpartum depression can be higher when screening scales are used because of some advantages in using questionnaires versus semi-structured interviews. For example, Buist et al..$^{6}$ argue that it is easier for the women to answer to a questionnaire than to speak about her depression, pointing advantages of questionnaires. Mothers may not express negative thoughts because of personal attributions or fear of the perceived consequences. Because the expectations of motherhood are usually associated with happiness, the discussion of negative aspects is often avoided ${ }^{7,8}$.

The fact is that the rates of postpartum depression can be quite different depending on the instrument that is used. In a preliminary study carried out in the city of Recife - Brazil, a total of 120 puerperium cases (60 users of the public health service and 60 of the private health service) were asked to fill in a Portuguese version of the EPDS and were later interviewed by an evaluator using a semi-structured interview for the diagnosis of depression with the DSM (Portuguese version of the Structured Clinical Interview for DSM-IV Axis I Disorders, known by its acronym, SCID-I). Considering the cut-off point at 12 in the EPDS, 25.8\% of puerperal women had depression. This number was much higher than that of 13.3\% found with the application of SCID-19. This study exemplifies how the depression rate can be overestimated when only screening scales are used in epidemiological studies.

Another factor that needs consideration in PPD prevalence studies is the postpartum time used to carry out the assessment of the symptoms. Some studies used a crosssection for the first two weeks of postpartum. This moment is inadequate to establish the PPD diagnosis due to the difficulty of distinguishing it from maternity blues, which is a very frequent mood instability state, typical of the first days of puerperium, which regresses spontaneously after one or two weeks ${ }^{10}$.

To our knowledge, six studies attempted to estimate the prevalence of postpartum depression in Brazil ${ }^{11-16}$. The aspects cited above appeared in one way or another in these studies, making the rates vary from $16 \%$ to $46 \%$. Four of the studies used the EPDS, one applied the BDI and the other used the Hamilton depression scale. Two of them did not exclude women in their first two weeks of postpartum. None of them have used an interview with the criteria of DSM-IV for depression.

Another important point is that the studies that reported risk factors and bio-socio-demographic data for PPD in our context were also based on screening scales and not on clinical interviews ${ }^{12-16}$. This aspect makes the result descriptions of the research terminologically confusing, especially with respect to the terms "depressive symptoms" and "depression diagnosis"17.

Therefore, knowing the PPD prevalence in Brazil by using a semi-structured instrument for diagnosis seems to be an important subject. The objective of this study was to use an interview to detect depression according to the criteria proposed by the DSM in puerperal women in child health care clinics in the city of Recife, together with the proper association of this disorder to bio-socio-demographic data based on these instruments. 


\section{METHOD}

The study used a cross-section method. It contained a convenience sample of 400 puerperal women.

The inclusion criteria were:

- women that were between 2 and 26 weeks of postpartum;

- women that voluntarily accepted to sign the terms of the informed consent;

- if they were under 18 years of age, they had a responsible individual accompanying them to sign the terms of consent;

- women that had babies considered healthy by themselves.

The choice of applying interviews on puerperal women with at least 2 weeks of postpartum had the intention of avoiding confusion between the symptoms of postpartum depression and the phenomenon of maternity blues. As there is no consensus as to the maximum time limit for considering the puerperium period, the limit of 26 weeks was opted for, according to most studies involving postpartum depression.

Also, to avoid any conflict between depression diagnosis and adjustment disorder, women whose babies had known developmental delays or incapacitating physical defects were not included.

\section{Period and sites of data collection}

The interviews were carried out during the period between November of 2007 and July of 2008, after due approval of the project by the local Research Ethics Board.

The intention was for the sample to be representative of the diverse socioeconomic status present in Brazil. For this, the choices for data collection sites were the following: two childcare public clinics, one being in the Clinical Hospital of the Federal University of Pernambuco (HC-UFPE), the other one in the Maternal Child Institute Professor Fernando Figueira (IMIP); and a private childcare office.

Both the HC-UFPE and the IMIP are institutions which attend patients from the public service system of Brazil. They both have infrastructure for health services as well as for teaching and research. They are considered reference centers in the state of Pernambuco (located in the Northeast of Brazil) and attend the highest demand in the region in their childcare clinics, taking patients from the whole metropolitan region of Recife (the capital of Pernambuco) and occasionally from other parts of the state. The great majority of these patients are low income status. The private clinic that was used for the data collection attends patients from various private health insurance plans. His patients are mostly from the middle class.

\section{Instruments}

\section{Bio-socio-demographic questionnaire}

This questionnaire was elaborated by the researchers. It had the objective of collecting data which characterized the sample in relation to age, civil status, educational level, family income, time of postpartum, parity, possible complications in pregnancy and delivery, current and past health problems, among others.

\section{Semi-structured clinical interview for diagnosing depression according to the criteria of the DSM-IV}

The Portuguese version of the Structured Clinical Interview for DSM-IV Axis I Disorders ${ }^{18}$ was used. More widely known by its acronym, SCID-I, this diagnostic interview has been extensively used in Psychiatric studies. The interview consists of standard questions distributed in modules corresponding to each disorder of the Axis I of the DSM. The test-retest reliability obtained fairly acceptable values. In an American study in which pairs of interviewers carried out independent diagnoses with 75 clinical patients, the concordance percentage was 82\% (kappa = 0.72) for major depressive episodes ${ }^{19}$. In Brazil, the inter-evaluator reliability using the translated Portuguese version was adequate. It obtained a kappa of 0.88 for depression ${ }^{18}$. The inter-evaluator reliability was also high with the use of SCID-I in studies with women during the postpartum period ${ }^{20}$.

The SCID-I is an instrument that is used by trained clinicians or health professionals. An interesting aspect of this interview is that, as it is semi-structured, it allows the evaluator to judge if there is or not the presence of any particular criterion, and also permits occasional adjustments in the way the questions are asked and/or the approach conducted. Eminent researchers of mental disorders of the puerperium period, recently proposed adaptations to this interview with respect to the approach used with women during pregnancy and in the postpartum period ${ }^{21}$.

The interviews were applied by two psychiatrists and by two medicine students under supervision with the psychiatrists. As SCID-I is a diagnosis interview that has already a reliability test in Brazil as cited above and as it is not a grading scale, we decided not to apply a reliability test for this study.

\section{STATISTICAL ANALYSIS}

To analyze the data, descriptive and inferential statistical techniques were used with the help of the Statistical Package for the Social Sciences (SPSS) program, version number 13. The descriptive statistical techniques involved absolute, percentual and odds ratio (OR) distributions. As an inferential statistical technique the Pearson's qui-square test was used. When the conditions to carry out the qui-square test were not satisfactory, the Fisher's exact test was used.

The confidence intervals were calculated for the prevalence of depression and for the OR. The significance level used in the decision of the statistical tests was of $5 \%$, and the confidence intervals were obtained with reliability of $95 \%$. 


\section{RESULTS}

Among the 400 puerperal women who participated in the study, 294 (73.5\%) were interviewed in public institutions (HC-UFPE and IMIP) and 106 (26.5\%) in the private clinic.

The interview was carried out with women of between 15 and 44 years of age, with a mean and median of 27 years and standard deviation (sd) of 6.0. With respect to the time of postpartum, they were in between the second and $26^{\text {th }}$ weeks, with a mean of 10 weeks $(s d=5.5)$ and median of nine weeks.

With regards to their civil status, 228 (85.5\%) of them were married or lived in consensual union. In relation to education, only $20 \%$ had completed higher education. Half of the women had some work activity. Nearly 35\% of them had a family income of up to a minimum wage.

Among the 400 puerperal women interviewed, 29 (7.2\% with a confidence interval between 4.7-9.8\%) presented major depression diagnosis according to the SCID-I. There were no statistically significant differences between the prevalence of depression in the public service (8.16\%) and the private service (4.72\%), with $p=0.241$. Also, from the 400 women, 24 (6.0\%) mentioned they had had a depressive episode in the past. From the 29 puerperal women that were depressed, six (20.7\%) mentioned that the symptoms of the current depressive episode initiated before pregnancy, 11 (37.9\%) during pregnancy; and 12 (41.4\%) after delivery.

When the group of depressed puerperal women was compared with the group of puerperal women without depression, no significant statistical differences were observed for data such as age, civil status, level of education (primary, secondary and higher education), family income (calculated by number of minimum wages), number of kids (counting the last one) and persons who depend on the income (Table 1).

In relation to the time of postpartum, the percentage of patients with depression was higher among the women evaluated with more than 8 weeks of postpartum than those evaluated with up to 8 weeks $(11.4 \% \times 4.0 \%)$. This difference reveals a significant association between the two variables being analyzed ( $p<0.05$; $O R=3.10$; and confidence interval which excludes the value 1.00). Regarding the weight at birth, the percentage of puerperal women with depression

Table 1. Association between the presence of depression and socio-demographic data

\begin{tabular}{|c|c|c|c|c|c|c|c|c|}
\hline \multirow{3}{*}{ Variable } & \multicolumn{4}{|c|}{ Major depression } & & & \multirow{3}{*}{ Value of $p$} & \multirow{3}{*}{$\mathrm{OR}$ (Cl to 95\%) } \\
\hline & \multicolumn{2}{|c|}{ Yes } & \multicolumn{2}{|c|}{ No } & \multicolumn{2}{|c|}{ Total } & & \\
\hline & $\mathrm{N}$ & $\%$ & $\mathrm{~N}$ & $\%$ & $\mathbf{n}$ & $\%$ & & \\
\hline \multicolumn{9}{|l|}{ Age } \\
\hline Up to 20 & 2 & 3.6 & 54 & 96.4 & 56 & 100.0 & \multirow[t]{3}{*}{$p=0.516$} & 1.00 \\
\hline 21 to 30 & 18 & 8.0 & 208 & 92.0 & 226 & 100.0 & & 2.34 (0.53 to 10.38) \\
\hline 31 or more & 9 & 7.6 & 109 & 92.4 & 118 & 100.0 & & 2.23 (0.46 to 10.68) \\
\hline \multicolumn{9}{|l|}{ Civil status } \\
\hline Single/widow/separated & 7 & 12.1 & 51 & 87.9 & 58 & 100.0 & \multirow[t]{3}{*}{$p=0.119$} & 1.49 (0.57 to 3.90$)$ \\
\hline Married & 8 & 4.5 & 168 & 95.5 & 176 & 100.0 & & 0.52 (0.21 to 1.27) \\
\hline Consensual union & 14 & 8.4 & 152 & 91.6 & 166 & 100.0 & & 1.00 \\
\hline \multicolumn{9}{|l|}{ Education } \\
\hline Primary incomplete & 3 & 7.1 & 39 & 92.9 & 42 & 100.0 & \multirow[t]{4}{*}{$p=0.576$} & $1.97(0.38$ to 10.24$)$ \\
\hline Primary complete & 7 & 7.6 & 85 & 92.4 & 92 & 100.0 & & $2.11(0.53$ to 8.46$)$ \\
\hline Secondary complete & 16 & 8.6 & 170 & 91.4 & 186 & 100.0 & & $2.42(0.68$ to 8.54$)$ \\
\hline Higher ed. Complete & 3 & 3.8 & 77 & 96.3 & 80 & 100.0 & & 1.00 \\
\hline \multicolumn{9}{|l|}{ Do you work? } \\
\hline Yes & 13 & 6.6 & 185 & 93.4 & 198 & 100.0 & \multirow[t]{2}{*}{$p=0.716$} & 1.00 \\
\hline No & 15 & 7.5 & 185 & 92.5 & 200 & 100.0 & & 1.15 (0.53 to 2.49$)$ \\
\hline \multicolumn{9}{|l|}{ Family income (MW) } \\
\hline Up to 1 & 12 & 8.5 & 129 & 91.5 & 141 & 100.0 & \multirow[t]{3}{*}{$p=0.713$} & $1.52(0.55$ to 4.19$)$ \\
\hline More than 1 to 5 & 11 & 7.1 & 144 & 92.9 & 155 & 100.0 & & $1.25(0.45$ to 3.49$)$ \\
\hline More than 5 & 6 & 5.8 & 98 & 94.2 & 104 & 100.0 & & 1.00 \\
\hline \multicolumn{9}{|c|}{ Number of persons who depend on the income } \\
\hline Up to 3 & 11 & 5.7 & 183 & 94.3 & 194 & 100.0 & \multirow[t]{3}{*}{$p=0.477$} & 1.00 \\
\hline 4 to 6 & 15 & 8.5 & 161 & 91.5 & 176 & 100.0 & & 1.55 (0.69 to 3.47) \\
\hline 7 or more & 3 & 10.0 & 27 & 90.0 & 30 & 100.0 & & 1.85 (0.48 to 7.05$)$ \\
\hline \multicolumn{9}{|c|}{ Number of kids counting with the last } \\
\hline 1 & 10 & 4.4 & 215 & 95.6 & 225 & 100.0 & \multirow[t]{3}{*}{$p=0.093$} & 1.00 \\
\hline 2 & 9 & 8.4 & 98 & 91.6 & 107 & 100.0 & & $1.97(0.78$ to 5.01$)$ \\
\hline 3 or more & 7 & 11.7 & 53 & 88.3 & 60 & 100.0 & & 2.84 (1.03 to 7.81) \\
\hline
\end{tabular}

MW: minimum wage; OR: odds ratio; Cl: confidence interval. 
was similar among those who had kids born with low and with normal weights $(7.6 \% \times 7.3 \%)$. Therefore no significant association can be derived from these variables ( $p>0.05$ ). The depression rate was 6.0\% higher in mothers who had normal deliveries in relation to those who had cesarean deliveries $(10.5 \% \times 4.5 \%)$. That was a significant association (OR $=2.55$ and interval that excludes 1.00). These results are accessible in table 2.

It is also possible to observe in table 2 that the prevalence of depression was higher among the mothers who had complications during pregnancy or delivery (such as preeclampsia, eclampsia, premature detachment of the placenta and placenta previa), compared with those who did not have complications $(10.6 \% \times 5.4 \%)$. It was also higher among the mothers whose babies had complications exactly after birth (such as pathological jaundice, infections and respiratory difficulties) $(9.3 \% \times 6.3 \%)$. The same was truth among mothers whose babies needed to be interned after birth $(9.5 \% \times 6.5 \%)$. However, at the level of $5.0 \%$ there is no proven significant association between high depression occurrence and these last variables.
Table 2 also shows that depression prevalence was higher among women whose pregnancy was not desired (10.1\% $\times 5.4 \%)$. Although at $5.0 \%$ significant association, it cannot be proven between the two variables of the analysis. That was higher among women who had spontaneous abortion than those who did not $(12.9 \% \times 5.6 \%)$. These results indicate significant association ( $p<0.05, \mathrm{OR}=2.52$ and confidence interval which varies from 1.16 to 5.49). It was also higher among women who had undergone treatment to become pregnant $(11.8 \% \times 7.1 \%)$, although without significant association.

Table 3 shows that prevalence of depression was highest among women who reported some sort of physical health problem than among those who did not $(15.1 \% \times 5.5 \%)$, showing that the association between health problem and the occurrence of depression is significant $(p<0.05, O R=$ 3.05). The depression rate was much higher among women who presented a history of psychiatric disorder when compared to those without $(32.4 \% \times 4.7 \%)$, difference which reveals a significant association $(p<0.001)$. Depression was also higher among women who presented a history of psychiatric disorder in the family ( $14.2 \% \times 4.6 \%)$

Table 2. Postpartum depression and data of pregnancy and neonatal period

\begin{tabular}{|c|c|c|c|c|c|c|c|c|}
\hline \multirow{3}{*}{ Variable } & \multicolumn{4}{|c|}{ Major depression } & & & \multirow{3}{*}{ Value of $p$} & \multirow{3}{*}{ OR (Cl to 95\%) } \\
\hline & \multicolumn{2}{|c|}{ Yes } & \multicolumn{2}{|c|}{ No } & \multicolumn{2}{|c|}{ Total } & & \\
\hline & $\mathrm{n}$ & $\%$ & $\mathrm{~N}$ & $\%$ & $\mathrm{n}$ & $\%$ & & \\
\hline \multicolumn{9}{|c|}{ Time of postpartum (in weeks) } \\
\hline Up to 8 & 9 & 4.0 & 216 & 96.0 & 225 & 100.0 & $p=0.004$ & 1.00 \\
\hline$>8$ & 20 & 11.4 & 155 & 88.6 & 175 & 100.0 & & 3.10 (1.37 to 6.98$)$ \\
\hline \multicolumn{9}{|c|}{ Weight of the child at birth } \\
\hline Up to 2500 & 5 & 7.6 & 61 & 92.4 & 66 & 100.0 & $p=1.000$ & 1.04 (0.38 to 2.83) \\
\hline$>2500$ & 24 & 7.3 & 304 & 92.7 & 328 & 100.0 & & 1.00 \\
\hline \multicolumn{9}{|l|}{ Type of delivery } \\
\hline Transpelvic & 17 & 10.8 & 140 & 89.2 & 157 & 100.0 & $p=0.016$ & 2.55 (1.16 to 5.60$)$ \\
\hline Cesarean & 11 & 4.5 & 231 & 95.5 & 242 & 100.0 & & 1.00 \\
\hline \multicolumn{9}{|c|}{ Complication during pregnancy or delivery } \\
\hline Yes & 15 & 10.6 & 126 & 89.4 & 141 & 100.0 & $p=0.055$ & $2.08(0.97$ to 4.43$)$ \\
\hline No & 14 & 5.4 & 244 & 94.6 & 258 & 100.0 & & 1.00 \\
\hline \multicolumn{9}{|c|}{ Baby with neonatal complications } \\
\hline Yes & 9 & 9.3 & 88 & 90.7 & 97 & 100.0 & $p=0.381$ & 1.44 (0.63 to 3.28$)$ \\
\hline No & 20 & 6.6 & 282 & 93.4 & 302 & 100.0 & & 1.00 \\
\hline \multicolumn{9}{|c|}{ Baby needed to stay interned after birth } \\
\hline Yes & 10 & 9.5 & 95 & 90.5 & 105 & 100.0 & $p=0.300$ & 1.52 (0.68 to 3.39$)$ \\
\hline No & 19 & 6.5 & 275 & 93.5 & 294 & 100.0 & & 1.00 \\
\hline \multicolumn{9}{|c|}{ Desired pregnancy } \\
\hline Yes & 14 & 5.4 & 246 & 94.6 & 260 & 100.0 & $p=0.077$ & 1.00 \\
\hline No & 14 & 10.1 & 124 & 89.9 & 138 & 100.0 & & $1.98(0.92$ to 4.29$)$ \\
\hline \multicolumn{9}{|c|}{ Past history of spontaneous abortion } \\
\hline Yes & 12 & 12.9 & 81 & 87.1 & 93 & 100.0 & $p=0.017$ & $2.52(1.16$ to 5.49$)$ \\
\hline No & 17 & 5.6 & 289 & 94.4 & 306 & 100.0 & & 1.00 \\
\hline \multicolumn{9}{|c|}{ Underwent treatment to become pregnant } \\
\hline Yes & 2 & 11.8 & 15 & 88.2 & 17 & 100.0 & $p=0.357$ & $1.74(0.38$ to 8.02$)$ \\
\hline No & 27 & 7.1 & 353 & 92.9 & 380 & 100.0 & & 1.00 \\
\hline
\end{tabular}

OR: odds ratio; Cl: confidence interval. 
Table 3. Association between postpartum depression and health problems

\begin{tabular}{|c|c|c|c|c|c|c|c|c|}
\hline \multirow{3}{*}{ Variable } & \multicolumn{4}{|c|}{ Major depression } & & & \multirow{3}{*}{ Value of $p$} & \multirow{3}{*}{ OR (Cl to 95\%) } \\
\hline & \multicolumn{2}{|c|}{ Yes } & \multicolumn{2}{|c|}{ No } & \multicolumn{2}{|c|}{ Total } & & \\
\hline & $\mathrm{N}$ & $\%$ & $\mathrm{n}$ & $\%$ & $\mathrm{~N}$ & $\%$ & & \\
\hline \multicolumn{9}{|c|}{ Has some physical health problem? } \\
\hline Yes & 8 & 15.1 & 45 & 84.9 & 53 & 100.0 & $p=0.017$ & 3.05 (1.26 to 7.38$)$ \\
\hline No & 19 & 5.5 & 326 & 94.5 & 345 & 100.0 & & 1.00 \\
\hline \multicolumn{9}{|c|}{ History of psychiatric disorder? } \\
\hline Yes & 12 & 32.4 & 25 & 67.6 & 37 & 100.0 & $p<0.001$ & 9.71 (4.18 to 22.57) \\
\hline No & 17 & 4.7 & 344 & 95.3 & 361 & 100.0 & & 1.00 \\
\hline \multicolumn{9}{|c|}{ History of psychiatric disorder in the family } \\
\hline Yes & 16 & 14.2 & 97 & 85.8 & 113 & 100.0 & $p=0.001$ & 3.41 (1.58 to 7.36$)$ \\
\hline No & 13 & 4.6 & 269 & 95.4 & 282 & 100.0 & & 1.00 \\
\hline
\end{tabular}

OR: odds ratio; Cl: confidence interval.

\section{DISCUSSION}

\section{Prevalence of postpartum depression}

The prevalence of postpartum depression in this sample was compatible with that of other research which used the SCID-I as the diagnostic instrument, rate which varies from $6 \%{ }^{22}$ to $12 \%{ }^{23}$. This result can demystify the myth that in Brazil the prevalence of postpartum depression is higher than in other countries. It allow the formulation of the hypothesis that these rates are approximately equal to those of other countries with more moderate percentages if the instrument used is the SCID-I (Table 4) shows this data, including the present study.

Possibly, because of the use of screening instruments with relatively low positive predictive value for the Brazilian population (in the concurrent validity with the SCID-I), the other Brazilian studies had higher rates than the one found in the present study, varying from $16 \%^{13}$ to $43 \%{ }^{12}$. As far as we know, this is the first time that a prevalence study of postpartum depression is carried out using a diagnostic interview in Brazil. Table 5 shows the data about the Brazilian studies, including the findings of this sampling.

Other factors related to some limitations of the present study, however, may have influenced the lower rate of PPD. The study was carried out in childcare clinics and a medical office. It is known that depression can lead to symptoms like lack of willingness, dismay, psychomotor slowness, social isolation and cognitive impairment, among others. These symptoms can occasionally be sufficiently intense to impair the ability or disposition of the puerperal woman to take her baby to pediatric consultations. Some women with more severe depression were not interviewed possibly because they were simply not found in the data collecting set. This could make this sample different from another sample carried out in the community, with interviews applied at the women's homes. Consequently the results of this study cannot be extrapolated to the general population; they are limited to child care clinics in Recife. Moreover, a convenience sample is not the most adequate way to conduct a prevalence study. Future researchers should consider replying this data in a more rigid sample selection.

Other relevant data is that nine women did not accept participation in the research study or did not sign the terms of consent. This data does not appear in the results because it was an exclusion criterion. However, it would not be unreasonable to suspect that some of these women had depressive symptoms and did not want to be interviewed because they were unwilling, irritated, or even fearful to speak their minds to the researchers. As we didn't use a qualitative approach to investigate this population we cannot make any definitive inference of these women. So we have to accept that they did not accept that perhaps because they just do not want to participate in the study for many other reasons. But it can be false.

Table 4. Prevalence of postpartum depression using the SCID-I

\begin{tabular}{lllll}
\hline Authors & Country & Prevalence $(\%)$ & Number of puerperal women evaluated & Period of evaluation \\
\hline Cantilino et al. & Brazil & 7 & 400 & 2nd to 26th week \\
Lee et al. ${ }^{22}$ & China & 6 & 959 & 3rd month \\
Regmi et al. ${ }^{23}$ & Nepal & 12 & 100 & 2nd to 3rd month \\
Yonkers et al. ${ }^{39}$ & United States & 7 & 802 & 3 rd to 5th week \\
Navarro et al. ${ }^{40}$ & Spain & 9 & 428 & 6 6th. week \\
Vega-Dienstmaier et al. ${ }^{41}$ & Peru & 6 & 321 & 1st year \\
\hline
\end{tabular}

SCID-I: Structured Interview for DSM Axis I. 
Table 5. Prevalence of depression and of postpartum depressive symptoms in Brazil

\begin{tabular}{|c|c|c|c|c|c|}
\hline Authors & City & Prevalence (\%) & Number of women evaluated & Period of evaluation & Instrument used \\
\hline Cantilino et al. & Recife & 7 & 400 & 2nd. to 26th week & SCID-I \\
\hline Cruz et al. ${ }^{11}$ & São Paulo & 37 & 70 & 12th to 16th week & EPDS $>11$ \\
\hline Da-Silva et al. ${ }^{12}$ & São Gonçalo & 43 & 21 & Up to 6th month & EPDS $>12$ \\
\hline Faisal-Cury et al. ${ }^{13}$ & São Paulo & 16 & 113 & 10th day & Beck Depression Inventory \\
\hline Moraes et al..$^{14}$ & Pelotas & 19 & 410 & 30th to 45th day & Depression scale of Hamilton $>17$ \\
\hline Ruschi et al..$^{15}$ & Vitória & 39 & 292 & 31 st to 180 th day & EPDS $>11$ \\
\hline Tannous et al. .16 $^{6}$ & Porto Alegre & 21 & 271 & 6th to 8th week & $E P D S>12$ \\
\hline
\end{tabular}

SCID: Structured Interview for DSM; EPDS: Edinburgh Postnatal Depression Scale.

It is also important to point out that those women were going to be with an interviewer with whom they were going to have a single contact. It is known that a psychiatric exam is based on an inter-subjective penetration of the spirit of the observer, who is looking to understand, and the spirit of the patient, who wants to be understood and gives himself/herself to the contact with the other. The affection exchanges of this relationship are instruments of evaluation. The fact that the interviewer would not be there to follow up her case could have affected the willingness of women to be interviewed.

\section{Association between postpartum depression and bio-socio-demographic data}

Regarding the relation between postpartum depression and age, it has been pointed out before that teenage puerperal women tend to present a higher rate of depression ${ }^{24}$. This was not observed in our sample, which curiously was made up of a mere $13 \%$ of women below the age of 20. Perhaps teenagers use the neighborhood services more than the larger services. Nevertheless, only two (3.6\%) among the 56 teenagers of the study presented a depressive framework.

The moment of postpartum in which the interview was carried out was important in relation to the rate of depression. Nearly $4 \%$ of puerperal women with less than 8 weeks were depressed, compared with $11.4 \%$ of those with more than 8 weeks. This substantiates the idea that PPD can be prolonged and that it does not necessarily start in the first four weeks after delivery, as the American Psychiatry Association suggests in its classification'.

The beginning of postpartum depression occurs usually in the first weeks of puerperium, being that great part of these women can present sub-syndromic symptomatology since gestation ${ }^{25}$. This disorder, however, does not limit itself to those first weeks as there does not seem to be a tendency for spontaneous symptomatological remission in the first months. A study which revised the literature during the period between 1982 and 2002 included studies which measured PPD or depression symptoms during postpartum, and at least another time between 6 to 30 months after the birth of the baby. The study showed that the depressive symptoms continued to cause problems in a significant number of mothers over 12 months after delivery ${ }^{26}$.

Researchers from various countries show that a significant percentage of mothers are depressed in the sixth month after delivery. In the United States, 35\% of women present important depressive symptoms during this period ${ }^{27}$. In Sweden, $13 \%$ of women remain depressed six months after the birth of their babies ${ }^{28}$. Between 6 and 12 months of postpartum, $15 \%$ of a sample of Australian mothers was depressed ${ }^{4,29}$.

The transpelvic delivery in our study was associated to postpartum depression when compared to the cesarean delivery. This goes against data of international research which associates cesarean surgery to depression ${ }^{30,31}$. Some factors could be responsible for this finding. One of them is that our medium women commonly consider the normal delivery a stressful experience. Some women report that they feel illassisted by the health group, that they have slow labors, that they have intense pain for long periods of time and some reported that during labor they feared the baby's death. It is possible that the current Brazilian health model does not offer adequate assistance to women during labor and that this makes them experience this moment as a situation of stress, insecurity and fear ${ }^{32}$. In developed countries, a great part of the transpelvic deliveries are carried out with analgesia. It has already been observed that the normal delivery, when carried out with analgesia, can significantly reduce the incidence of depressive symptoms during the postpartum ${ }^{33}$. Prolonged pain during delivery can increase cortisol level which is also related to the stress level experienced ${ }^{34}$. Another factor that can explain this disparity is that in our medium, differently from that of developed countries, great part of cesarean deliveries is programmed. It is observed, however, that international studies associate postpartum depression especially to emergency cesarean surgeries ${ }^{31}$.

Past history of spontaneous abortion was associated to postpartum depression in our study. A hypothesis that can elucidate this phenomenon is the fact that $6 \%$ of the puerperal women of our sample mentioned that they already had had depression in the past. From the puerperal women 
with PPD, nearly 20\% reported that their symptoms initiated before pregnancy, which suggest a protracted depressive framework. It is known that depression during pregnancy is related to a higher rate of spontaneous abortions $\mathrm{s}^{35}$. It is possible that many of these women were depressed during the pregnancies that generated abortions. Moreover, a German study showed that women with a previous spontaneous abortion history present significant higher levels of anxiety and stress during subsequent pregnancy than those without this history. There exists an assumption that these abortions can lead to adverse psychological consequences in predisposed women ${ }^{36}$. Pathological anxiety during pregnancy is considered one of the strongest predictors of postpartum depression ${ }^{37}$.

Our data also substantiate the idea that depression is related to diverse clinical diseases, to a past history of psychological disorders (especially anxiety and mood disorders) and to the family history of mental disorders ${ }^{38}$. However, associations between current and past depressive episodes as well as between current depressive episode and health problems, history of disorders, etc. were based in the women reports (and not in independent measures as medical records) and could be distorted by her actual mood.

\section{CONCLUSIONS}

The prevalence of depression in postpartum women in child care clinics in Recife-Brazil is of 7.2\%. The present study used the SCID-I for the diagnosis and the rate was lower than that reported by studies which used screening scales to assess this estimate. A past history of psychiatric disorders, a family history of psychiatric disorder and the presence of physical health problems were associated with depression. Women with a past history of spontaneous abortion, those who had a transpelvic birth and those over 8 weeks of puerperium also had a higher prevalence of depression.

\section{ACKNOWLEGEMENTS}

We thank the pediatrician José Henrique Silva and his secretary, Kátia. We also thank the puericulture services of Hospital das Clínicas - UFPE and of IMIP.

No conflict of interest related to this article.

\section{REFERENCES}

1. American-Psychiatric-Association. DSM-IV-TR - Manual diagnóstico e estatístico de transtornos mentais. Porto Alegre: Artmed; 2002.

2. Kumar R, Robson KM. A prospective study of emotional disorders in childbearing women. Br J Psychiatry. 1984;144:35-47.
3. Halbreich U, Karkun S. Cross-cultural and social diversity of prevalence of postpartum depression and depressive symptoms. J Affect Disord. 2006;91:97-111.

4. Cox JL, Holden JM, Sagovsky R. Detection of postnatal depression. Development of the 10-item Edinburgh Postnatal Depression Scale. Br J Psychiatry. 1987;150:782-78.

5. Beck AT, Ward CH, Mendelson M, Mock J, Erbaugh J. An inventory for measuring depression. Arch Gen Psychiatry. 1961;4:561-71.

6. Buist A, Condon J, Brooks J, Speelman C, Milgrom J, Hayes B, et al. Acceptability of routine screening for perinatal depression. J Affect Disord. 2006;93:233-7.

7. Hall PL, Papageorgiou C. Negative thoughts after childbirth: development and preliminary validation of a self-report scale. Depress Anxiety. 2005;22:121-9.

8. Hall PL, Wittkowski A. An exploration of negative thoughts as a normal phenomenon after childbirth. J Midwifery Womens Health. 2006;51:321-30.

9. Cantilino A, Sougey EB, Maia A, Albuquerque C, Cantilino G. Validação da Escala de Depressão Pós-parto de Edinburgh (versão em português) no Nordeste do Brasil. In: Psiquiatria AB ed, XXI Congresso Brasileiro de Psiquiatria. Goiânia; 2003.

10. Kennerley H, Gath D. Maternity blues. I. Detection and measurement by questionnaire. Br J Psychiatry. 1989;155:356-62

11. Cruz EBdS, Simões GL, Faisal-Cury A. Rastreamento da depressão pós-parto em mulheres atendidas pelo Programa de Saúde da Família. Rev Bras Ginecol Obstet. 2005;27:181-8.

12. Da-Silva VA, Moraes-Santos AR, Carvalho MS, Martins ML, Teixeira NA. Prenatal and postnatal depression among low income Brazilian women. Braz J Med Biol Res. 1998:31:799-804.

13. Faisal-Cury A, Tedesco JJ, Kahhale S, Menezes PR, Zugaib M. Postpartum depression: in relation to life events and patterns of coping. Arch Womens Ment Health. 2004;7:123-31.

14. Moraes IG, Pinheiro RT, Silva RA, Horta BL, Sousa PL, Faria AD. [Prevalence of postpartum depression and associated factors]. Rev Saude Publica. 2006;40:65-70.

15. Ruschi GEC, Sun SY, Mattar R, Chambô Filho A, Zandonade E, Lima VJ. Aspectos epidemiológicos da depressão pós-parto em amostra brasileira. Rev Psiquiatr Rio Gd Sul. $2007: 29: 274-80$

16. Tannous L, Gigante LP, Fuchs SC, Busnello ED. Postnatal depression in Southern Brazil: prevalence and its demographic and socioeconomic determinants. BMC Psychiatry. 2008;8:1.

17. Spanemberg L. Depressão pós-parto: considerações terminológicas. Rev Psiquiatr Rio Gd Sul. 2008;30:85-6.

18. Del-Ben CM, Vilela JAA, Crippa JAdS, et al. Confiabilidade da "Entrevista Clínica Estruturada para o DSM-IV - Versão Clínica" traduzida para o português. Rev Bras Psiquiatr. 2001;23:156-9.

19. Riskind JH, Beck AT, Berchick RJ, Brown G, Steer RA. Reliability of DSM-III diagnoses for major depression and generalized anxiety disorder using the structured clinical interview for DSM-III. Arch Gen Psychiatry. 1987;44:817-20.

20. O'Hara MW, Zekoski EM, Philipps LH, Wright EJ. Controlled prospective study of postpartum mood disorders: comparison of childbearing and nonchildbearing women. J Abnorm Psychol. 1990;99:3-15.

21. Gorman LL, O'Hara MW, Figueiredo B, Hayes S, Jacquemain F, Kammerer MH, et al. Adaptation of the structured clinical interview for DSM-IV disorders for assessing depression in women during pregnancy and post-partum across countries and cultures. Br J Psychiatry Suppl. 2004;46:s17-23.

22. Lee D, Yip A, Chiu H, Leung T, Chung T. A psychiatric epidemiological study of postpartum Chinese women. Am J Psychiatry. 2001;158:220-6.

23. Regmi S, Sligl W, Carter D, Grut W, Seear M. A controlled study of postpartum depression among Nepalese women: validation of the Edinburgh Postpartum Depression Scale in Kathmandu. Trop Med Int Health. 2002;7:378-82.

24. Cantilino A, Barbosa EM, Petribu K. Postpartum depression in adolescents in Brazil: an issue of concern. Arch Womens Ment Health. 2007;10:307-8.

25. Stowe ZN, Hostetter AL, Newport DJ. The onset of postpartum depression: implications for clinical screening in obstetrical and primary care. Am J Obstet Gynecol. 2005;192:522-6.

26. Goodman JH. Postpartum depression beyond the early postpartum period. J Obstet Gynecol Neonatal Nurs. 2004;33:410-20.

27. Beeghly M, Weinberg MK, Olson KL, Kernan H, Riley J, Tronick EZ. Stability and change in level of maternal depressive symptomatology during the first postpartum year. J Affect Disord. 2002;71:169-80 
28. Josefsson A, Berg G, Nordin C, Sydsjo G. Prevalence of depressive symptoms in late pregnancy and postpartum. Acta Obstet Gynecol Scand. 2001;80:251-5.

29. Hiscock H, Wake M. Infant sleep problems and postnatal depression: a community-based study. Pediatrics. 2001;107:1317-22.

30. Hannah P, Adams D, Lee A, Glover V, Sandler M. Links between early post-partum mood and post-natal depression. Br J Psychiatry. 1992;160:777-80.

31. Boyce PM, Todd AL. Increased risk of postnatal depression after emergency caesarean section. Med J Aust. 1992;157:172-4.

32. Zambaldi CF. Sintomas obsessivo-compulsivos na depressão pós-parto. In: Pós-graduação em Neuropsiquiatria e Ciências do Comportamento. Recife: Universidade Federal de Pernambuco; 2008. p. 85.

33. Hiltunen P, Raudaskoski T, Ebeling H, Moilanen I. Does pain relief during delivery decrease the risk of postnatal depression? Acta Obstet Gynecol Scand. 2004;83:257-61.

34. Mahomed K, Gulmezoglu AM, Nikodem VC, Woman WL, Chalmers BE, Hofmeyr Gj. Labor experience, maternal mood and cortisol and catecholamine levels in low-risk primiparous women. J Psychosom Obstet Gynaecol. 1995;16:181-6.
35. Sugiura-Ogasawara M, Furukawa TA, Nakano Y, Hori S, Aoki K, Kitamura T. Depression as a potential causal factor in subsequent miscarriage in recurrent spontaneous aborters. Hum Reprod. 2002;17:2580-4.

36. Bergner A, Beyer R, Klapp BF, Rauchfuss M. Pregnancy after early pregnancy loss: a prospective study of anxiety, depressive symptomatology and coping. J Psychosom Obstet Gynaecol. 2008;29:105-13.

37. Beck CT. Predictors of postpartum depression: an update. Nurs Res. 2001;50:275-85.

38. Martin M, Baca E, Alvarez E, et al. Risk factors and outcome predictors in the long-term depression. Actas Esp Psiquiatr. 2008;36(Suppl 2):12-8.

39. Yonkers KA, Ramin SM, Rush AJ, Navarrete CA, Carmody T, March D, et al. Onset and persistence of postpartum depression in an inner-city maternal health clinic system. Am J Psychiatry. 2001;158:1856-63.

40. Navarro P, Garcia-Esteve L, Ascaso C, Aguado J, GelabertE, Martín-Santos R. Non-psychotic psychiatric disorders after childbirth: prevalence and comorbidity in a community sample. J Affect Disord. 2008;109:171-6.

41. Vega-Dienstmaier JM, Mazzotti G, Stucchi-Portocarrero S, Campos M. [Prevalence and risk factors for depression in postpartum women]. Actas Esp Psiquiatr. 1999;27:299-303. 